\title{
QR CODES COMO FERRAMENTA INTERATIVA E FACILITADORA DO PROCESSO DE ENSINO E APRENDIZAGEM
}

\author{
Marília Stylianoudakis \\ IFTM/Uberlândia \\ marilia0403@gmail.com \\ Ricardo Soares Bôaventura \\ IFTM/Uberlândia \\ ricardoboaventura@iftm.edu.br
}

Resumo: Este trabalho aborda a questão do uso dos de celulares no ambiente escolar como instrumento facilitador do processo ensino-aprendizagem. Estamos vivenciando um momento de trasição da implementação da tecnologia na educação, podemos perceber que não existe um caminho traçado a seguir, porém nos deparamos com o desafio dos celulares presentes em sala de aula e com o dilema proibir X explorar. Diante desse cenário buscamos formas de explorar o uso de celulares em sala de aula, mostrar para os discentes que é possível aprender utilizando o celular. A proposta desse artigo é de aplicação na área de matemática e funciona como uma caça ao tesouro por meio de QR codes (é uma espécie de código de barras que pode armazenar informações, fotos, mídias, dentre outros), seria confeccionado QR codese em seguida os espalhariamos pela escola esses por sua vez conteriam cálculos matemáticos, por meio do celular os alunos descodificadiam esse código e teriam acesso a operação a ser resolvida. O resultado dessa operação seria a quantidade de metros que o aluno teria que percorrer até o próximo $Q R$ code, com o auxilio de uma trena ele poderá mensurar o caminho e com uma bússula a direção a seguir. O presente trabalho irá abordar temas da matemática, unidades de medida e orientação, ou seja, podemos trabalhar de forma interdiciplinar mostrando para os discentes que existe formas de aprender com o auxilio do celular e conciliar esse entrave que existe entre os novos meios de comunicação e o ambiente sala de aula.

\section{Introdução}


A ampla utilização da tecnologia em nossa sociedade transcende a comunicação rápida entre as pessoas, visto que tornou-se imprescindível para qualquer tipo de interação social, hoje há uma necessidade do uso dessa em todos os espaços sociais. Sem contrariar esta corrente, ela, a tecnologia, também chegou à escola, assim, tornou-se necessário discutir o modo de utilizá-la para fomentar/incrementar/impulsionar novas atividades motivadoras e desafiadoras para os alunos. Partindo desse pressuposto, propomos a utilização de QR codes como material de apoio para o ensino dos conteúdos da disciplina de matemática.

Segundo uma pesquisa da Agência Nacional do Brasil (EBC 2016) ${ }^{25}$, 80\% dos jovens brasileiros de 9 a 17 anos usam a internet e $83 \%$ deles a acessam via celular. Logo, percebe-se o quanto a utilização desse aparelho tem aumentado e despertado cada vez mais o interesse das crianças, adolescentes, bem como adultos.

Ao pensar nessa proposta, fizemos várias pesquisas e nos pareceu um caminho coerente, para atrair tal interesse destes jovens, alunos da rede pública do ensino fundamental, utilizar o método "Bring Your Own Device" ou traga seu próprio dispositivo. Trata-se uma metodologia que permite aos usuários em espaços como empresas ou escolas a acessarem suas redes digitais por meio de seus próprios dispositivos móveis. Procurando viabilizar a utilização da tecnologia em sala de aula com recursos limitados, alcançando bons resultados no contexto da escola pública brasileira, logo, ele aparece um meio de conseguir superar o desafio da falta de recursos financeiros.

Vale destacar que no universo tecnológico existem diversas ferramentas que podem ser exploradas com o intuito de ensinar, como as ferramentas do Google, as demais redes sociais, Whatsapp, entre outros. Neste artigo escolhemos falar sobre os QR Codes e o modo como eles poderam ser utilizados em sala de aula com propostas de sua aplicabilidade para o ensino da matemática.

\section{O universo do docente com recursos tecnológicos}

\footnotetext{
25 Dados retirados da "Pesquisa: $80 \%$ da população brasileira entre 9 e 17 anos usam a internet"O trabalho foi realizado pelo Comitê Gestor da Internet no Brasil (CGI.br), através do Centro Regional de Estudos para o Desenvolvimento da Sociedade da Informação (Cetic.br).Foram entrevistados 6,1 mil entrevistas presenciais com crianças e adolescentes e 3 mil com pais ou responsáveis,
} 
Sabe-se que o uso da tecnologia na atualidade é de grande valia na educação, essa otimiza o processo de ensino-aprendizagem. Está claro que as ferramentas digitais, por mais que sejam, muitas vezes, mal vistas pelos profissionais da área da educação, podem ser decisivas, quando bem utilizadas.

O uso de celulares, especialmente, pode auxiliar o aluno na organização da sua vida acadêmica, bem como no momento das pesquisas, para desenvolver trabalhos, visto que esse é uma ferramenta rápida e, atualmente, completa ( conta com acesso a internet, calculadora entre outros aplicativos). Pode-se dizer que este instrumento tem ganhado espaço no ambiente escolar, segundo Bock (2010), "condenado pelos incômodos gerados no ambiente escolar, o telefone celular está prestes a se transformar em um aliado no processo de aprendizagem, segundo um estudo de um grupo de pesquisadores internacionais".

Com a implantação da tecnologia no ambiente escolar, Atualmente surgiu outra modalidade de aprendizado e acesso a conteúdos, chamado "mobile learning", uma otimização do e-learning, a diferença é que ocorre por meio do uso de aparelhos móveis (como celulares, tablets e notebooks). Ou seja, esta forma inovadora de aprender, consiste em utilizar estes recursos como um novo ambiente de troca de conhecimentos, fácil, rápido e acessível. Pode-se usar o "mobile learning" em qualquer hora e lugar, acessar programas educacionais, assistir vídeos educacionais e etc. Vale destacar que quando se usa este recurso como aliado da educação escolar seu uso deve ser muito bem mediado pelo professor para que não se perca a funcionalidade e o discente disperse utilizando "apps" que nada acrescenta no momento de estudo e os alunos consigam atingir os objetivos propostos a eles.

\subsection{0 ensino da matemática por meio da tecnologia}

Com a finalidade de aprimorar os recursos disponibilizados pela escola, assume-se, como interesse principal, mostrar aos professores o quanto pode ser amplo os recursos oferecidos pelas mídias e como pode-se utilizá-los com intuito de otimizar do ensino de matemática. Assim, o ensino torna-se mais prazeroso, lúdico e, principalmente, mostra aos alunos a importância da tecnologia e seu uso consciente.

Sabe-se que o aluno é um sujeito ativo na construção de seu conhecimento, na estruturação de sua inteligência; ele aprende a partir de suas ações e reflexões, em interações com o outro, com o ambiente e deve ser respeitado como um ser que tem o direito de viver o seu próprio tempo.Acredita-se que o jogo é um excelente recurso para 
ajudar o aluno a construir suas novas descobertas, desenvolver e enriquecer sua personalidade e é um instrumento pedagógico que dá condições ao professor de ser condutor, estimulador e avaliador da aprendizagem. Não se pode negar o aspecto de diversão e de prazer que o jogo oferece (LUPINACCI, s/d).

Assim, tem-se nas tecnologias uma ferramenta importante e conhecida pelos alunos. Isto facilita o entendimento e, também, desfaz o estranhamento que muitos discentes possuem de determinadas teorias e métodos de aprendizado.

A matemática, muitas vezes, aparece como uma disciplina complexa para os alunos do ensino regular. Embora considerada por muitos discentes importante no currículo escolar, as atividades matemáticas são consideradas difíceis e pouco lúdicas. Desse modo é importante, para incentivar o estudo, reverter a perspectiva e tabus que envolvem o ensino de matemática, o que exige, cada vez mais, criatividade dos educadores.

Ensinar matemática é (re)criar estratégias e apropriar a linguagem à realidade dos alunos, de modo que a experiência destes possam ser valorizadas no momento da aprendizagem. Assim, cabe ao educador criar ou aprimorar métodos e ferramentas, que transmitem e ensinam conteúdos matemáticos.

\subsection{O que são QR Codes?}

QR code significa Quick Response Code (algo como Código de Resposta Rápida) funciona como um código de barras de duas dimensões o que o diferencia do tradicional (aquele presente nas embalagens de produtos), além disso, sua capacidade de armazenamento que é muito maior podendo armazenar até mais de 4 mil caracteres ou mais de 7 mil números. Esses códigos surgiram com a finalidade de disseminar a informação. Eles foram criados em 1994 pela empresa japonesa DensoWave para identificar peças na indústria automobilística.

Sua maior finalidade tem sido fazer link entre uma mídia impressa (como jornais e revistas) e uma mídia online (internet), ou seja, por meio do $Q R$ Code faz-se o encaminhamento de um material impresso para um digital, podemos armazenar uma informação de modo a torná-la pública. 
Existem programas para decodificar um código QR code para a grande maioria dos celulares com câmeras. Nestes aparelhos basta abrir o programa e apontar a câmera para o código que será decodificado imediatamente.

\subsection{Proposta de aula utilizando QR Code- Metodologia}

A proposta será para a disciplina de Matemática, o público alvo será os alunos do $8^{\circ}$ ano do ensino fundamental da rede pública e o conteúdo em questão será operações com números reais.

Em um primeiro momento ensinaremos os alunos sobre o que é um $Q R$ code e mostraremos como é simples armazenar uma informação nesse código de barras. No segundo momento dividiremos os alunos em grupos para sanar o problema de nem todos possuírem celular, posteriormente solicitaremos a eles que instalem o leitor de $Q R$ code em suas casas e também que tragam uma trena e uma bússola .

A atividade proposta será uma caça ao tesouro. Por meio de seu dispositivo móvel o aluno utilizará o leitor do código para ter acesso às informações nele contidas. O QR code com tais informações será fornecido pelo professor ao início da aula, assim, os alunos terão que resolver as operações fornecidas pelo código descobrindo quantos metros e em que direção terão que caminhar até o próxima pista ( $Q R$ code) com mais informações do trajeto a ser percorrido. Os alunos terão, para mensurar a distância, acesso a uma trena e para se direcionar, para tanto utilizarão uma bússola. A atividade funcionará como uma competição,por isso serão criados quatro caminhos para um mesmo destino, o grupo que chegar primeiro ao tesouro ganhará um prêmio simbólico.

\section{Considerações Finais}

O uso de códigos $Q R$, baseado no conceito do Mobile Learning, poderão dar um novo enfoque aos processos de ensino e aprendizagem, introduzindo uma nova dinâmica que trará motivação para os alunos estudarem. Além disso, o seu uso poderá quebrar as barreiras físicas associadas à escola e extrapolar a aquisição de conhecimentos para ambientes não formais.

Com esse tipo de atividade podemos "gameficar" o ensino fazendo uma competição saudável, que incentive os alunos a dar seu melhor, para que percebam 
que o uso de recursos tecnológicos de modo consciente e mediado, podem trazer uma nova maneira de aprendizado.

Há na educação, nos dias de hoje, uma dificuldade em lidar com o uso de celulares dentro de sala de aula. Desse modo, surgem alguns questionamentos a respeito desse uso. Como lidar com esse momento de transição? Quais caminhos seguir? Proibir ou liberar o uso da tecnologia? São questionamentos difíceis de responder, porém quando nos deparamos com o mundo informatizado e globalizado é inquestionável que devemos investir na tecnologia, incorporá-la no processo ensinoaprendizadem, por isso passamos a buscar formas de fazer com que o celular não se torne nosso inimigo, mas sim nosso aliado.

\section{Referências}

CAVAlCANTE, S. Rafaela; MARCELINO, B. C. Maria. Tecnologias Móveis em Educação: o uso do celular na sala de aula . Disponível em: <http://www.fatea.br/seer/index.php/eccom/article/viewFile/596/426> Acesso:04/2017

NICHELE, Aline Grunewald Nichele; SCHLEMMER, Eliane e RAMOS, Adriana de Farias. QR Codes na Educação em Química. Renote - Novas Tecnologias na Educação.v. 13, n. 2 (2015). Disponível in: < http://www.seer.ufrgs.br/index.php/renote/article/view/61425/36318 > ISSN 16791916.

PINHEIRO, C. Regina; RODRIGUES, L. Márcia.O uso do celular do celular como recurso pedagógico nas aulas de língua portuguesa. Disponível em: <http://www.filologia.org.br/revista/52/ RPh52.pdf\#page=122> Acesso: 04/2017

RENOTE - Novas Tecnologias na Educação, v. 10, n. 3, dezembro, 2012.

SACCOL, A.; SCHLEMMER, E.; BARBOSA, J. M-learning e u-learning: novas perspectivas das aprendizagens móvel e ubíqua. São Paulo: Pearson Prentice Hall, 2011.

SANTOS, Núbia dos Santos Rosa Santana dos; LIMA, José Valdeni de; WIVES, Leandro Krug. Integração de recursos para acesso aos objetos de aprendizagem multimodais.

VIEIRA, Liliana de Souza; COUTINHO, Clara Pereira. Mobile Learning: Perspetivando o potencial dos códigos QR na educação. CIEd - Textos em volumes de atas de encontros científicos nacionais e internacionais (2013). Disponível in: <http://hdl.handle.net/1822/25450> Acesso: 04/2017

MELLO, Daniel. Pesquisa: $80 \%$ da população brasileira entre 9 e 17 anos usam a internet.Disponível 
inovacao/noticia/2016-10/pesquisa-80-da-populacao-brasileira-entre-9-e-17-anosusam> Acesso: 04/2017 